\title{
Viabilidade econômica da adubação adicional de genótipos de feijoeiro em relação ao resíduo de adubação da batata(1)
}

\author{
Hamilton Kikuti(2), Messias José Bastos de Andrade ${ }^{(3)}$, Magno Antônio Patto Ramalho(4) \\ e Ângela de Fátima Barbosa Abreu ${ }^{(5)}$
}

\begin{abstract}
Resumo - O objetivo deste trabalho foi avaliar a viabilidade econômica de genótipos de feijoeiro, com e sem adubação adicional, em relação à adubação residual da batata. Foram conduzidos, em Lavras, MG, quatro experimentos com o feijão em sucessão à cultura da batata. Em cada safra (águas 98/99 e invernoprimavera 99) foi instalado um experimento utilizando apenas a adubação residual da batata e outro que utilizou, além do mencionado resíduo, uma adubação para o feijoeiro, de $500 \mathrm{~kg} \mathrm{ha}^{-1}$ da formula 4-14-8 na semeadura e $40 \mathrm{~kg} \mathrm{ha}^{-1} \mathrm{de} \mathrm{N}$ (sulfato de amônia) em cobertura. O delineamento experimental foi látice 5 x 5, com três repetiç̃es, seis cultivares comerciais e 19 linhagens utilizadas no programa de melhoramento do feijoeiro da Universidade Federal de Lavras. A análise conjunta mostrou que os genótipos de feijoeiro apresentaram comportamento não coincidente em resposta à adubação. Em ambas as safras, a adubação adicional do feijoeiro elevou o rendimento de grãos, mas apenas na safra de inverno-primavera mostrou-se economicamente viável. Os resultados evidenciaram, ainda, a possibilidade de se obterem bons rendimentos de grãos com a cultura do feijoeiro utilizando apenas a adubação residual da batata. Termos para indexação: Phaseolus vulgaris, cultivo seqüencial, rotação de cultura, rendimento.
\end{abstract}

\section{Economic viability of additional fertilization of bean genotype in relation to residual potato fertilization}

\begin{abstract}
The objective of this work was to evaluate the economic viability of bean genotype, with and without the additional fertilization, in relation to the residual potato fertilization. Four experiments with bean in rotation of potato crop were conducted in Lavras, MG, Brazil. In each crop (summer 98/99 and winter-spring 99 season) two experiments were set up: the first using only the residual potato fertilization and the other using, besides the mentioned residue, a fertilization for the bean plant of $500 \mathrm{~kg} \mathrm{ha}^{-1}$ of the fertilizer with 4-14-8 formulation at planting and $40 \mathrm{~kg} \mathrm{ha}^{-1}$ of $\mathrm{N}$ top dressing under the form of ammonium sulfate. The experimental design was a $5 \times 5$ lattice with three replications, evaluating six commercial cultivars and 19 strains used in the bean plant breeding program of the Universidade Federal de Lavras. The joint analysis showed that the bean genotype presented noncoincident behavior in response to fertilization. In both seasons the fertilization of the legume raised grain yield but only in the winter-spring crop it proved to be economically viable. The results also showed that it is possible to obtain a good bean yield utilizing only the residual potato fertilization. Index terms: Phaseolus vulgaris, sequential cropping, rotational cropping, yields.
\end{abstract}

(1) Aceito para publicação em 30 de julho de 2001 Extraído da dissertação de mestrado apresentada pelo primeiro autor à Universidade Federal de Lavras (Ufla), Lavras, MG Parcialmente financiado pela Fundação de Amparo à Pesquisa do Estado de Minas Gerais (Fapemig)

(2) Ufla, Departamento de Agricultura, Caixa Postal 37 CEP 37200-000 Lavras, MG. E-mail: kikuti@ufla.br

(3) Ufla, Departamento de Agricultura. Bolsista do CNPq. E-mail: mandrade@ufla.br

(4) Ufla, Departamento de Biologia. Bolsista do CNPq E-mail: magnoapr@ufla.br

(5) Embrapa-Centro Nacional de Pesquisa de Arroz e Feijão, Caixa Postal 179, CEP 75375-000 Santo Antônio de Goiás, GO. E-mail: afbabreu@ufla.br

\section{Introdução}

A batata (Solanum tuberosum L.) ocupa a terceira posição entre os alimentos utilizados mundialmente para a nutrição humana (Filgueira, 1993), e na região sul de Minas Gerais é a hortaliça que mais sobressai, tanto em extensão de áreas cultivadas como em preferência alimentar, o que torna esta região a maior produtora do Estado.

Por se tratar de cultura com incidência de graves problemas fitossanitários, requer constante rotação com outras espécies, de modo a contribuir para o 
controle de pragas e patógenos. Além disso, requer elevada quantidade de fertilizantes, que pode atingir até $6 \mathrm{t}$ ha-1 (Ribeiro, 1999), o que permite considerável aproveitamento residual pela cultura em rotação.

Na região, tem sido crescente o interesse na rotação da batata com a cultura do feijoeiro, que constitui-se uma ótima opção para o bataticultor, aliando as vantagens de ciclo curto e fácil comercialização, e boa rentabilidade econômica, normalmente na proximidade de grandes centros consumidores.

Em geral, a cultura do feijoeiro apresenta respostas à adubação, notadamente ao P e N (Silveira \& Moreira, 1990; Barbosa Filho \& Silva, 1994; Fronza et al., 1994; Peres et al., 1994; Carvalho et al., 1995; Barbosa Filho \& Silva, 2000). Da mesma forma, também têm sido registradas respostas ao efeito residual da adubação quando a cultura anterior é o próprio feijoeiro (Goepfert, 1972). Embora existam relatos de resposta diferencial das cultivares de feijoeiro à adubação utilizada (Stone \& Pereira, 1994; Garrido, 1998; Piana et al., 1999), há carência de informação sobre a resposta diferencial de cultivares/linhagens de feijoeiro ao efeito residual da adubação realizada na cultura anterior.

Este trabalho teve como objetivo avaliar o desempenho de genótipos de feijoeiro em relação à adubação residual da batata e a viabilidade econômica da rotação batata-feijão.

\section{Material e Métodos}

O estudo constou de quatro experimentos de campo com a cultura do feijoeiro em sucessão à cultura da batata, em Lavras, MG. Os dois primeiros experimentos foram semeados em novembro de 1998 (safra das águas) e os outros dois, em julho de 1999 (safra do inverno-primavera), em área experimental do Departamento de Biologia da Universidade Federal de Lavras (Ufla), em um Latossolo Vermelho distroférrico, típico, de textura muito argilosa, horizonte A moderado, mesodistrófico oxídico (Andrade, 1979; Embrapa, 1999), cujos resultados da análise química estão apresentados na Tabela 1 . As análises foram realizadas nos laboratórios do Departamento de Ciência do Solo da Ufla e interpretados de acordo com a Comissão de Fertilidade do Solo do Estado de Minas Gerais (1999).

As culturas de batata que precederam os experimentos foram conduzidas de julho a outubro de 1998 e de dezembro de 1998 a abril de 1999. A adubação de plantio foi equivalente a $3 \mathrm{t} \mathrm{ha}^{-1}$ do fertilizante na fórmula 4-14-8, e a de cobertura, $300 \mathrm{~kg} \mathrm{ha}^{-1}$ de sulfato de amônio, mais $160 \mathrm{~kg} \mathrm{ha}^{-1}$ de cloreto de potássio. A cultura foi conduzida com os tratos culturais normalmente dispensados à lavoura da batata em Minas Gerais, e a irrigação realizada por aspersão convencional.

Na primeira safra, o feijão foi semeado logo após a colheita da batata, e na segunda, três meses após. As amostras de solos $(0-20 \mathrm{~cm})$ foram coletadas por ocasião do preparo do solo para a leguminosa. O preparo do solo e o manejo da cultura foram idênticos em todos os experimentos.

Em cada safra foram conduzidos dois experimentos em áreas contíguas: um, sem adubação da cultura do feijoeiro, utilizando apenas a adubação residual da batata; e o outro, no qual o feijão recebeu $500 \mathrm{~kg} \mathrm{ha}^{-1}$ da fórmula NPK (4-14-8), contendo ainda $10 \%$ de $\mathrm{Ca}, 0,09 \%$ de B e $0,3 \%$ de $\mathrm{Zn}$. Neste último, foi também realizada uma adubação em cobertura com $40 \mathrm{~kg} \mathrm{ha}^{-1}$ (sulfato de amônio) aos 22 dias após a emergência.

O delineamento estatístico empregado em cada ensaio foi o látice $5 \times 5$, com três repetições. Os tratamentos, em número de 25 , constituíram-se de seis cultivares comerciais: Emgopa-Ouro, Ouro Negro, Carioca, Pérola, Carioca-MG e IAPAR 81, e 19 linhagens do grupo carioca, pertencentes ao programa de melhoramento do feijoeiro da Ufla: CII-102, LH-11, LH-9, LH-10, CII-348, CII-175, CII-90, CII-337, ESAL-696, CII-281, LH-2, CII-244, ESAL-695, CII-103, LH-3, ESAL-693, CII-78, B-1 e ESAL-694. As parcelas foram constituídas de duas linhas de $5 \mathrm{~m}$ de comprimento, a espaços de $0,50 \mathrm{~m}$, com densidade de 12 plantas por metro linear.

Em ambas as safras foi avaliado o rendimento de grãos $\left(\mathrm{kg} \mathrm{ha}^{-1}\right)$, corrigido para $13 \%$ de umidade. Todos os dados obtidos foram inicialmente submetidos a análise individual por experimento e, posteriormente, em conjunto. As comparações entre médias foram feitas pelo teste de Duncan a $\mathbf{5 \%}$ de probabilidade; e para classificar as cultivares/linhagens, utilizou-se o procedimento proposto por Fasoulas (1983), que estima o valor Pi, isto é, a porcentagem das cultivares/linhagens que foram superadas estatisticamente por determinada cultivar/linhagem.

Os resultados do rendimento de grãos foram ainda submetidos a uma análise econômica com base nos custos da adubação adicional do feijão, considerando-se as demais 
despesas como comuns. Considerou-se como custo efetivo o produto dos preços unitários dos fertilizantes, pelas quantidades correspondentes que seriam gastas para um hectare de lavoura. Para isto, foram utilizados os preços médios dos últimos cinco anos, em dólares. A produção de grãos foi a correspondente à média dos experimentos adubado ou não adubado, expressa em $\mathrm{kg} \mathrm{ha}^{-1}$. A renda bruta, que consiste na multiplicação entre o preço e a quantidade produzida em cada caso, foi expressa em US\$ ha ${ }^{-1}$, e calculada a partir do preço da saca de feijão, em dólares, obtido no período de dez anos.

A margem bruta foi estimada para cada situação, conforme Alvarez Venegas (1985), com base no modelo matemático $\mathrm{MB}=\mathrm{P}_{\mathrm{y}} \mathrm{Y}-\mathrm{P}_{\mathrm{x} 1} \mathrm{X}_{1}-\mathrm{P}_{\mathrm{x} 2} \mathrm{X}_{2}$, em que: $\mathrm{MB}$ : margem bruta (US\$ ha ${ }^{-1}$ ); $\mathrm{P}_{\mathrm{y}}$ : preço do feijão (US\$ kg-1); Y: produção do feijão $\left(\mathrm{kg} \mathrm{ha}^{-1}\right) ; \mathrm{X}_{1}$ : dosagem do fertilizante formulado 4-14-8 $\left(\mathrm{kg} \mathrm{ha}^{-1}\right)$; $\mathrm{X}_{2}$ : dosagem de sulfato de amônio ( $\left.\mathrm{kg} \mathrm{ha}^{-1}\right) ; \mathrm{P}_{\mathrm{x} 1}$ : preço do 4-14-8 (US\$ kg-1); e $\mathrm{P}_{\mathrm{x} 2}$ : preço do sulfato de amônio (US\$ kg-1).

\section{Resultados e Discussão}

A análise de variância conjunta revelou baixo valor do coeficiente de variação, $18,13 \%$, em comparação com os freqüentemente obtidos na região com a cultura do feijoeiro (Abreu et al., 1994), o que indica uma boa precisão experimental. Quanto às fontes de variação, houve efeito significativo $(\mathrm{P} \leq 0,01)$ de sa- fras e cultivares/linhagens, bem como das interações safras x cultivares/linhagens, cultivares/ linhagens x adubação e safras x adubação.

Os rendimentos de grãos obtidos na safra das águas foram superiores à média da região, $522 \mathrm{~kg} \mathrm{ha}^{-1}$ (Santos \& Braga, 1998) (Tabela 2). Esses resultados podem ser atribuídos às condições climáticas na maturação e colheita, quando não ocorreram excessos de chuva, principal fator responsável pelas baixas produtividades obtidas nessa safra na região (Andrade et al., 1992). Nessa safra, em particular, maiores precipitações ocorreram após a colheita do feijão e a temperatura média não ultrapassou $25^{\circ} \mathrm{C}$. Contudo, os maiores rendimentos médios de grãos, independentemente do genótipo e adubação, foram obtidos na safra de inverno, quando as condições são mais favoráveis à cultura, com temperaturas mais amenas e água suprida por irrigação (Andrade, 1998).

O comportamento dos genótipos não foi coincidente nas duas safras (Tabela 2). Na safra das águas, os genótipos mais produtivos foram CII-102, Ouro Negro, Pérola e CII-348, enquanto no inverno-primavera se destacaram Carioca-MG, LH-11 e LH-10. Considerando-se a média das duas safras e o valor $\mathrm{Pi}$, a linhagem CII-102 (2.584 kg ha-1) foi a que mais se

Tabela 1. Resultados da análise química de amostras $(0-20 \mathrm{~cm})$ de solos dos experimentos de feijão, em duas safras. Ufla, Lavras, MG, 1998/99(1).

\begin{tabular}{|c|c|c|c|c|c|}
\hline Características & Águas 98/99 & Inverno 99 & Características & Águas 98/99 & Inverno 99 \\
\hline pH em água $(1: 2,5)$ & $4,8(\mathrm{AcE})$ & $5,8(\mathrm{AcM})$ & $\mathrm{Zn}\left(\mathrm{mg} \mathrm{dm}^{-3}\right)$ & $26,4(\mathrm{~A})$ & $5,5(\mathrm{~A})$ \\
\hline $\mathrm{P}\left(\mathrm{mg} \mathrm{dm}^{-3}\right)$ & 20,0 (MBo) & 28,0 (MBo) & $\mathrm{Cu}\left(\mathrm{mg} \mathrm{dm}^{-3}\right)$ & $3,29(\mathrm{~A})$ & $2,8(\mathrm{~A})$ \\
\hline $\mathrm{K}\left(\mathrm{mg} \mathrm{dm}^{-3}\right)$ & $111,0(\mathrm{Bo})$ & 140,0 (MBo) & $\operatorname{Mn}\left(\mathrm{mg} \mathrm{dm}^{-3}\right)$ & $16,7(\mathrm{~A})$ & $5,2(\mathrm{M})$ \\
\hline $\mathrm{Ca}\left(\mathrm{cmol}_{\mathrm{c}} \mathrm{dm}^{-3}\right)$ & $1,7(\mathrm{M})$ & $2,3(\mathrm{M})$ & $\mathrm{Fe}\left(\mathrm{mg} \mathrm{dm}^{-3}\right)$ & $35,5(\mathrm{Bo})$ & $17,3(\mathrm{Ba})$ \\
\hline $\operatorname{Mg}\left(\mathrm{cmol}_{\mathrm{c}} \mathrm{dm}^{-3}\right)$ & $0,5(\mathrm{M})$ & 1,1 (Bo) & $\mathrm{S}-\mathrm{SO}_{4}\left(\mathrm{mg} \mathrm{dm}^{-3}\right)$ & 18,9 (MBo) & 33,7 (MBo) \\
\hline $\mathrm{Al}\left(\mathrm{cmol}_{\mathrm{c}} \mathrm{dm}^{-3}\right)$ & $0,0(\mathrm{MBa})$ & $0,0(\mathrm{MBa})$ & $\mathrm{Ca} / \mathrm{T}(\%)$ & 24,3 & 34,5 \\
\hline $\mathrm{H}+\mathrm{Al}\left(\mathrm{cmol}_{\mathrm{c}} \mathrm{dm}^{-3}\right)$ & $4,5(\mathrm{M})$ & $2,9(\mathrm{M})$ & $\mathrm{Mg} / \mathrm{T}(\%)$ & 7,2 & 16,5 \\
\hline S.B. $\left(\mathrm{cmol}_{\mathrm{c}} \mathrm{dm}^{-3}\right)$ & $2,5(\mathrm{M})$ & 3,8 (Bo) & $\mathrm{K} / \mathrm{T}(\%)$ & 4,1 & 5,4 \\
\hline $\mathrm{t}\left(\mathrm{cmol}_{\mathrm{c}} \mathrm{dm}^{-3}\right)$ & $2,5(\mathrm{M})$ & $3,8(\mathrm{M})$ & $\mathrm{Ca} / \mathrm{Mg}$ & 3,4 & 2,1 \\
\hline $\mathrm{T}\left(\mathrm{cmol}_{\mathrm{c}} \mathrm{dm}^{-3}\right)$ & $7,0(\mathrm{M})$ & $6,7(\mathrm{M})$ & $\mathrm{Ca} / \mathrm{K}$ & 6,0 & 6,4 \\
\hline $\mathrm{m}(\%)$ & $0,0(\mathrm{MBa})$ & $0,0(\mathrm{MBa})$ & $\mathrm{Mg} / \mathrm{K}$ & 1,8 & 3,1 \\
\hline $\mathrm{V}(\%)$ & $35,6(\mathrm{Ba})$ & $56,4(\mathrm{M})$ & Mat. org. (dag kg $\left.{ }^{-1}\right)$ & $2,9(\mathrm{M})$ & $3,1(\mathrm{M})$ \\
\hline $\mathrm{B}\left(\mathrm{mg} \mathrm{dm}^{-3}\right)$ & $0,4(\mathrm{M})$ & $0,5(\mathrm{M})$ & $\mathrm{Na}\left(\mathrm{mg} \mathrm{dm}^{-3}\right)$ & 0,1 & 5,5 \\
\hline
\end{tabular}

(1)AcE: acidez elevada; AcM: acidez média; A: teor alto; MBo: muito bom; Bo: bom; M: médio; Ba: baixo; MBa: muito baixo; S: soma de bases; t: CTC efetiva; T: CTC a pH 7,0; m: saturação de Al; V: porcentagem de saturação de bases da CTC a pH 7,0; a interpretação dos resultados foi feita conforme Comissão de Fertilidade do Solo do Estado de Minas Gerais (1999). 
destacou, superando estatisticamente $80 \%$ dos genótipos testados. Além dela, merecem destaque os genótipos Pérola (2.533 $\left.\mathrm{kg} \mathrm{ha}^{-1}\right)$, Ouro Negro (2.474 $\left.\mathrm{kg} \mathrm{ha}^{-1}\right)$, LH-11 (2.453 kg ha-1) e Carioca-MG (2.446 kg ha-1).

Todas as cultivares/linhagens apresentaram melhor desempenho na safra de inverno-primavera. $\mathrm{O}$ acréscimo médio de produtividade nessa safra, em relação à das águas foi de $61 \%$, refletindo as condições mais favoráveis à cultura nessa época. Houve, no entanto, diferenças quantitativas entre os genótipos na resposta à melhora de ambiente nessa safra. As maiores respostas foram observadas em ESAL-694 e Carioca-MG, e as menores, em Ouro Negro e CII-102.
O comportamento dos genótipos também foi diferenciado em relação ao efeito da adubação residual (Tabela 3). O incremento variou de $-0,8 \%$ em 'B- 1 ' a $67 \%$ em 'ESAL-696'. Os coeficientes de correlação entre os rendimentos com $(r=0,74)$ e sem $(r=0,40)$ adubação do feijoeiro, na safra das águas e na safra inverno-primavera, respectivamente, revelaram um comportamento diferencial dos genótipos por causa da adubação do feijoeiro, especialmente nesta última (Tabela 2). Esse comportamento diferencial já havia sido relatado por Ronzelli Júnior et al. (1985), Silva (1988), Miranda (1993), Barbosa Filho \& Silva (1994), Stone \& Pereira (1994) e Barbosa Filho \& Silva (2000).

Tabela 2. Rendimento médio de grãos de 25 genótipos de feijoeiro sem e com adubação, na safra das águas (1998/ 1999) e na safra de inverno-primavera (1999), após o cultivo adubado de batata. Ufla, Lavras, MG, 1998/99.

\begin{tabular}{|c|c|c|c|c|c|c|c|c|c|c|}
\hline \multirow[t]{2}{*}{ Genótipo $^{(1)}$} & \multicolumn{4}{|c|}{ Águas } & \multicolumn{4}{|c|}{ Inverno-primavera } & \multirow{2}{*}{$\begin{array}{l}\text { Média } \\
\text { geral }\end{array}$} & \multirow[t]{2}{*}{$\mathrm{Pi}$} \\
\hline & $\begin{array}{c}\text { Sem } \\
\text { adubo }\end{array}$ & $\begin{array}{c}\text { Com } \\
\text { adubo }\end{array}$ & Média & $\mathrm{Pi}^{(2)}$ & $\begin{array}{c}\text { Sem } \\
\text { adubo }\end{array}$ & $\begin{array}{c}\text { Com } \\
\text { adubo }\end{array}$ & Média & $\mathrm{Pi}$ & & \\
\hline & --------- & $-(\mathrm{kg} \mathrm{ha}$ & --------- & $(\%)$ & ---------- & $\left.\mathrm{kg} \mathrm{ha}^{-1}\right)$ & ------- & $(\%)$ & $\left(\mathrm{kg} \mathrm{ha}^{-1}\right)$ & $(\%)$ \\
\hline CII-102 & 2.210 & 2.448 & 2.330 & 84 & 2.638 & 3.040 & 2.840 & 8 & 2.584 & 80 \\
\hline Pérola & 2.080 & 2.120 & 2.100 & 68 & 2.188 & 3.742 & 2.966 & 16 & 2.533 & 68 \\
\hline Ouro Negro & 2.172 & 2.462 & 2.316 & 84 & 2.068 & 3.192 & 2.630 & 0 & 2.474 & 68 \\
\hline LH-11 & 1.416 & 1.792 & 1.604 & 12 & 2.318 & 4.286 & 3.602 & 52 & 2.453 & 68 \\
\hline Carioca-MG & 1.252 & 1.614 & 1.432 & 4 & 2.666 & 4.252 & 3.458 & 76 & 2.446 & 68 \\
\hline LH-9 & 1.808 & 1.566 & 1.686 & 12 & 2.766 & 3.478 & 3.122 & 36 & 2.404 & 64 \\
\hline LH-10 & 1.174 & 1.748 & 1.462 & 4 & 2.728 & 3.818 & 3.272 & 48 & 2.367 & 60 \\
\hline CII-348 & 1.918 & 2.208 & 2.064 & 68 & 1.886 & 3.422 & 2.660 & 0 & 2.362 & 60 \\
\hline Carioca & 1.880 & 1.590 & 1.740 & 12 & 2.140 & 3.372 & 2.756 & 4 & 2.248 & 36 \\
\hline CII- 175 & 1.734 & 1.948 & 1.842 & 20 & 2.542 & 2.590 & 2.566 & 0 & 2.204 & 32 \\
\hline CII-90 & 1.502 & 1.592 & 1.546 & 12 & 1.982 & 3.630 & 2.806 & 8 & 2.176 & 28 \\
\hline CII-337 & 1.372 & 1.618 & 1.494 & 4 & 2.168 & 3.434 & 2.800 & 8 & 2.147 & 24 \\
\hline ESAL-696 & 1.318 & 1.880 & 1.598 & 12 & 1.868 & 3.440 & 2.654 & 0 & 2.127 & 24 \\
\hline CII-281 & 1.420 & 2.114 & 1.766 & 12 & 1.764 & 3.174 & 2.470 & 0 & 2.118 & 24 \\
\hline LH-2 & 1.542 & 1.826 & 1.684 & 12 & 1.900 & 3.148 & 2.524 & 0 & 2.104 & 20 \\
\hline CII-244 & 1.678 & 1.852 & 1.764 & 12 & 1.736 & 3.112 & 2.424 & 0 & 2.094 & 20 \\
\hline ESAL-695 & 1.472 & 1.866 & 1.670 & 12 & 2.016 & 2.798 & 2.406 & 0 & 2.038 & 16 \\
\hline IAPAR-81 & 1.546 & 1.716 & 1.630 & 12 & 1.876 & 2.880 & 2.378 & 0 & 2.004 & 8 \\
\hline EMGOPA-Ouro & 1.372 & 1.734 & 1.552 & 12 & 1.976 & 2.884 & 2.430 & 0 & 1.991 & 8 \\
\hline CII-103 & 1.296 & 992 & 1.144 & 0 & 1.870 & 3.564 & 2.716 & 0 & 1.930 & 8 \\
\hline LH-3 & 1.298 & 1.654 & 1.476 & 4 & 1.584 & 3.092 & 2.338 & 0 & 1.907 & 8 \\
\hline ESAL-693 & 1.166 & 1.680 & 1.428 & 4 & 1.760 & 2.804 & 2.282 & 0 & 1.855 & 8 \\
\hline CII-78 & 1.668 & 1.566 & 1.618 & 12 & 1.600 & 2.520 & 2.060 & 0 & 1.839 & 8 \\
\hline B-1 & 1.138 & 1.150 & 1.444 & 0 & 2.218 & 2.182 & 2.200 & 0 & 1.672 & 4 \\
\hline ESAL-694 & 828 & 910 & 870 & 0 & 1.434 & 2.776 & 2.104 & 0 & 1.487 & 0 \\
\hline Médias & 1.530 & 1.746 & 1.639 & & 2.068 & 3.225 & 2.647 & & 2.143 & \\
\hline
\end{tabular}

(1)Ouro Negro: grupo preto; EMGOPA-Ouro: grupo amarelo; demais cultivares/linhagens: grupo mulatinho. (2) Pi: porcentagem de genótipos que foram superadas estatisticamente pelo genótipo i (genótipo em análise), pelo teste de Duncan a 5\% de probabilidade. 
Independentemente da safra e dos genótipos, a utilização do adubo no feijoeiro proporcionou au-

Tabela 3. Rendimento médio $\left(\mathrm{kg} \mathrm{ha}^{-1}\right)$ de grãos de 25 genótipos de feijoeiro, sem e com adubação, após o cultivo adubado da batata. Ufla, Lavras, MG, 1998/99(1)

\begin{tabular}{|c|c|c|c|}
\hline Genótipo $^{(2)}$ & Sem adubação & Com adubação & Resposta $(\%)^{(3)}$ \\
\hline CII-102 & 2.424 & 2.744 & 13,2 \\
\hline Pérola & 2.134 & 2.932 & 37,4 \\
\hline Ouro Negro & 2.120 & 2.828 & 33,4 \\
\hline LH-11 & 1.867 & 3.040 & 62,8 \\
\hline Carioca-MG & 1.959 & 2.932 & 49,7 \\
\hline LH-9 & 2.286 & 2.522 & 10,3 \\
\hline LH-10 & 1.951 & 2.784 & 42,7 \\
\hline CII-348 & 1.908 & 2.816 & 47,6 \\
\hline Carioca & 2.016 & 2.480 & 23,0 \\
\hline CII-175 & 2.138 & 2.270 & 6,2 \\
\hline CII-90 & 1.742 & 2.610 & 49,8 \\
\hline CII-337 & 1.769 & 2.526 & 42,8 \\
\hline ESAL-696 & 1.593 & 2.660 & 67,0 \\
\hline CII-281 & 1.592 & 2.644 & 66,1 \\
\hline LH-2 & 1.721 & 2.486 & 44,5 \\
\hline CII-244 & 1.707 & 2.482 & 45,4 \\
\hline ESAL-695 & 1.744 & 2.332 & 33,7 \\
\hline IAPAR-81 & 1.711 & 2.298 & 34,3 \\
\hline EMGOPA-Ouro & 1.674 & 2.310 & 38,0 \\
\hline CII-103 & 1.583 & 2.278 & 43,9 \\
\hline LH-3 & 1.441 & 2.372 & 64,6 \\
\hline ESAL-693 & 1.463 & 2.248 & 53,7 \\
\hline CII-78 & 1.634 & 2.042 & 25,0 \\
\hline B-1 & 1.678 & 1.665 & $-0,8$ \\
\hline ESAL-694 & 1.131 & 1.843 & 63,0 \\
\hline Média & 1.799 & 2.486 & 38,2 \\
\hline
\end{tabular}

(1) Média de duas safras (águas 1998/99 e inverno-primavera 1999). (2) Ouro Negro (grupo preto); EMGOPA-Ouro (grupo amarelo) e demais genótipos (grupo mulatinho). ${ }^{(3)}$ Indica a porcentagem de resposta à adubação do feijoeiro pela cultivar considerada mento médio de $38,2 \%$ no rendimento de grãos, em relação ao tratamento sem adubo (Tabela 3 ). Contudo, a resposta à adubação foi mais pronunciada na semeadura do inverno, quando o incremento foi de $56 \%$, em relação a apenas $14 \%$ nas águas (Tabela 2 ).

Tais resultados mostram a necessidade do uso da adubação adicional; contudo, é necessário verificar se há retorno econômico no investimento. Nas duas condições em que foram conduzidos os experimentos, a única diferença foi a adubação do feijoeiro; assim, o retorno econômico foi estimado considerando apenas essa característica (Tabela 4). Na safra das águas, a máxima produção foi verificada quando se utilizou o fertilizante adicional, obtendo-se uma renda bruta equivalente a US\$ $1.175,06$ por hectare, e de US\$ $1.029,67$ por hectare quando se utilizou apenas a adubação residual. Neste último caso o retorno líquido foi negativo, indicando, assim, não ser economicamente viável a adubação do feijoeiro em sucessão à batata, quando a semeadura é realizada na época das águas.

$\mathrm{Na}$ safra de inverno-primavera, a renda bruta foi US\$ $2.170,43$ por hectare com a adubação, e de US\$ $1.391,76$ por hectare quando se utilizou apenas o efeito residual da adubação da batata. O retorno líquido obtido pela diferença das margens foi equivalente a US\$ 603,67 por hectare, o que viabiliza, nessa safra, o emprego da adubação do feijoeiro cultivado em sucessão à batata. Os riscos do empreendimento são menores, justifica-se um maior investimento.

Tabela 4. Custo dos fertilizantes usados em plantio e em cobertura, produção estimada, renda obtida, margem bruta calculada e diferença entre essa margem e a referente ao tratamento que utilizou apenas o efeito residual da adubação da batata, em duas safras do feijoeiro, sem e com adubação.

\begin{tabular}{|c|c|c|c|c|}
\hline \multirow[t]{2}{*}{ Especificação } & \multicolumn{2}{|c|}{ Safra das águas de 1998/99 } & \multicolumn{2}{|c|}{ Safra de inverno-primavera de 1999} \\
\hline & Sem adubação & Com adubação & Sem adubação & Com adubação \\
\hline $\begin{array}{l}\text { Custo do fertilizante: plantio + } \\
\text { cobertura }\left(\mathrm{US} \$ \mathrm{ha}^{-1}\right)^{(1)}\end{array}$ & 0,00 & 175,00 & 0,00 & 175,00 \\
\hline Produção estimada $\left(\mathrm{kg} \mathrm{ha}^{-1}\right)$ & $1.530,00$ & $1.746,00$ & $2.068,00$ & $3.225,00$ \\
\hline Renda bruta (US\$ ha $\left.{ }^{-1}\right)^{(2)}$ & $1.029,69$ & $1.175,06$ & $1.391,76$ & $2.170,43$ \\
\hline Margem bruta (US\$ $\mathrm{ha}^{-1}$ ) & $1.029,69$ & $1.000,06$ & $1.391,76$ & $1.995,43$ \\
\hline Diferença das margens (US\$ ha ${ }^{-1}$ ) & & $-29,63$ & & 603,67 \\
\hline
\end{tabular}

(1) Preço médio na região de Lavras, MG, nos últimos cinco anos: 4-14-8: US\$ 0,248 kg-1; sulfato de amônio: US\$ 0,255 kg-1 (2) Preço médio do feijão na região de Lavras, MG, nos últimos dez anos: US\$ $0,673 \mathrm{~kg}^{-1}$. 


\section{Conclusões}

1. O comportamento dos genótipos de feijoeiro em resposta à adubação adicional é diferenciado.

2. A adubação residual da cultura da batata permite a obtenção de boas produtividades da cultura do feijoeiro em sucessão.

3. Comparada à adubação residual, a adubação adicional da cultura do feijoeiro eleva o rendimento de grãos.

\section{Referências}

ABREU, A. de F. B.; RAMALHO, M. A. P.; SANTOS, J. B. dos.; MARTINS, L. A. Progresso do melhoramento genético do feijoeiro: nas décadas de setenta e oitenta nas regiões sul e Alto Paranaíba em Minas Gerais. Pesquisa Agropecuária Brasileira, Brasília, v. 23, n. 1, p. 105-112, jan. 1994.

ALVAREZ VENEGAS, V. H. Avaliação da fertilidade do solo: superfície de resposta: modelos aproximativos para expressar a relação fator-resposta. Viçosa, MG: UFVImprensa Universitária, 1985.75 p.

ANDRADE, H. Caracterização genética, morfológica e classificação de dois solos do Município de LavrasMG em correlação com a geomorfologia da área. 1979. 84 f. Dissertação (Mestrado) - Escola Superior de Agricultura de Lavras, Lavras. 1979.

ANDRADE, M. J. B. de. Clima e solo. In: VIEIRA, C.; PAULA JÚNIOR, T. J. de; BORÉM, A. (Ed.). Feijão: aspectos gerais e cultura no Estado de Minas Gerais. Viçosa: UFV, 1998. p. 83-97.

ANDRADE, M. J. B. de; ABREU, A. de F. B.; RAMALHO, M. A. P. Recomendação para a cultura do feijoeiro em Minas Gerais. Lavras: Esal, 1992. 12 p. (Circular, 6).

BARBOSA FILHO, M. P.; SILVA, O. F. da. Adubação e calagem para o feijoeiro irrigado em solo de cerrado. Pesquisa Agropecuária Brasileira, Brasília, v. 35, n. 7, p. 1317-1324, jul. 2000.

BARBOSA FILHO, M. P.; SILVA, O. F. da. Aspectos agroeconômicos da calagem e da adubação nas culturas de arroz e feijão irrigados por aspersão. Pesquisa Agropecuária Brasileira, Brasília, v. 29, n. 1. 1, p. 1657 1667, nov. 1994.

CARVALHO, A. M.; FAGERIA, N. K.; OLIVEIRA, I. P.; KINJO, T. Resposta do feijoeiro à aplicação de fósforo em solos dos cerrados. Revista Brasileira de Ciência do Solo, Campinas, v. 19, n. 1, p. 61-67, jan./abr. 1995.

COMISSÃO DE FERTILIDADE DO SOLO DO ESTADO DE MINAS GERAIS (Lavras, MG). Recomendações para o uso de corretivos e fertilizantes em Minas Gerais: 5⿳. aproximação. Lavras, 1999. 359 p.

EMBRAPA. Centro Nacional de Pesquisa de Solos (Rio de Janeiro, RJ). Sistema brasileiro de classificação de solos. Brasília: Embrapa-SPI, 1999. 412 p.

FASOULAS, A. C. Rating cultivars and trials in applied plant breeding. Euphytica, Dordrecht, v. 32, n. 3, p. 939943, Nov. 1983.

FILGUEIRA, F. A. R. Nutrição mineral e adubação em bataticultura, no Centro-Sul. In: SIMPÓSIO SOBRE NUTRIÇÃO E ADUBAÇÃO DE HORTALIÇAS, 1990, Jaboticabal. Anais... Piracicaba: Potafos, 1993. p. 401428.

FRONZA, V.; VIEIRA, V.; CARDOSO, A. A.; CRUZ, C. D.; PEREIRA, P. R. G. Resposta de cultivares de feijão (Phaseolus vulgaris L.) de porte ereto ao efeito de espaçamento entre linhas e níveis de adubação mineral. Revista Ceres, Viçosa, v. 41, n. 237, p. 567-583, set./out. 1994.

GARRIDO, M. A. T. Respostas do feijoeiro às lâminas de água e adubação nitrogenada. 1998. 205 f. Tese (Doutorado) - Universidade Federal de Lavras, Lavras. 1998.

GOEPFERT, C. F. Experimento sobre o efeito residual da adubação fosfatada em feijoeiro (Phaseolus vulgaris L.). Agronomia Sulriograndense, Porto Alegre, v. 8, n. 1, p. 41-47, 1972.

MIRANDA, G. V. Comparação de métodos de avaliação da adaptabilidade e estabilidade do comportamento de cultivares: exemplo com a cultura do feijão (Phaseolus vulgaris L.). 1993. 120 f. Dissertação (Mestrado) - Universidade Federal de Viçosa, Viçosa. 1993.

PERES, J. R. R.; SUHET, A. R.; MENDES, I. C.; VARGAS, M. A. T. Efeito da inoculação de rizóbio e da adubação nitrogenada em sete cultivares de feijão em solo de cerrado. Revista Brasileira de Ciência do Solo, Campinas, v. 18, n. 3, p. 415-420, set./dez. 1994.

PIANA, C. F. de B.; ANTUNES, I. F.; SILVA, J. G. C. da; SILVEIRA, E. P. Adaptabilidade e estabilidade do rendimento de grãos de genótipos de feijão. Pesquisa Agropecuária Brasileira, Brasília, v. 34, n. 4, p. 553564, abr. 1999. 
RIBEIRO, J. D. R. Associativismo garante futuro do produtor de batatas. Informe Agropecuário, Belo Horizonte, v. 20, n. 197, p. 5-6, mar./abr. 1999.

RONZELLI JÚNIOR, P.; VIEIRA, C.; BRAGA, J. M.; SEDIYAMA, C. S. Resposta de cultivares de feijão (Phaseolus vulgaris L.) à calagem e adubação fosfatada. Revista Ceres, Viçosa, v. 32, n. 184, p. 500-524, nov./ dez. 1985.

SANTOS, M. L.; BRAGA, M. J. Aspectos econômicos. In: VIEIRA, C.; PAULA JÚNIOR., T. J.; BORÉM, A (Ed.). Feijão: aspectos gerais e cultura no Estado de Minas Gerais. Viçosa, MG: UFV, 1998. p. 19-53.
SILVA, A. J. da. Resposta de cultivares de feijão (Phaseolus vulgaris L.) à adubação nitrogenada. 1988. 85 f. Dissertação (Mestrado) - Escola Superior de Agricultura de Lavras, Lavras. 1988.

SILVEIRA, P. M.; MOREIRA, J. A. A. Resposta do feijoeiro a doses de fósforo e lâminas de água de irrigação. Revista Brasileira de Ciência do Solo, Campinas, v. 14, n. 1, p. 63-67, jan./abr. 1990.

STONE, L. F.; PEREIRA, A. L. Sucessão arroz-feijão irrigados por aspersão: efeitos de espaçamento entre linhas, adubação e cultivar na produtividade e nutrição do feijoeiro. Pesquisa Agropecuária Brasileira, Brasília, v. 29, n. 4, p. 521-533, abr. 1994. 